\title{
"Vai, Meninas!"- Uma iniciativa para fomentar a participação das mulheres nos cursos da área de tecnologia da informação
}

\author{
Suelen M. de Paula ${ }^{1}$, Raylla L. S. Gama ${ }^{1}$, Isabella A. D. Melo ${ }^{1}$, \\ Adrielly C. E. Dias ${ }^{1}$, Daniela C. Terra ${ }^{1}$, Leticia M. M. S. Cheloni ${ }^{1}$ \\ ${ }^{1}$ Departamento de Computação \\ Instituto Federal de Minas Gerais (IFMG) \\ R. Afonso Sardinha, 90 - Ouro Branco, MG - Brasil \\ \{suelen.mapa, daniela.terra, leticia.cheloni\}@ifmg.edu.br, \\ \{isamelo.d, adriellyclaradias\}@gmail.com, raylla_opl2@hotmail.com
}

\begin{abstract}
Women are still in a minority position in technological areas, especially in the academy. In IFMG, for example, only $22.7 \%$ information system undergraduate students are female, and their participation in this course has decreased over the years. To increase women's participation, a new learning program was established: "Vai, Meninas!". This educational intervention achieved relevant results, increasing the current students' motivation by disseminating support culture and developing new practices to share and generate knowledge among the students.
\end{abstract}

Resumo. As mulheres ainda representam uma minoria na área de tecnologia, especialmente no meio acadêmico. Por exemplo, no IFMG - campus Ouro Branco apenas $22.7 \%$ dos estudantes de sistemas de informação são mulheres, e a entrada delas nesse curso tem diminuído ao longo dos anos. Para buscar aumentar a participação das mulheres, foi criado o projeto de ensino "Vai, Meninas!". Trata-se de um programa de intervenção educacional que alcançou resultados positivos, aumentando a motivação das atuais alunas, através da disseminação da cultura de apoio mútuo, compartilhamento e geração de novos conhecimentos entre elas.

\section{Introdução}

Cursos relacionados a ciências exatas, sobretudo engenharia e tecnologia da informação (TI), estão se desenvolvendo e crescendo significativamente nas últimas décadas. No entanto, observa-se que as mulheres ainda representam uma minoria nessas áreas, especialmente no meio acadêmico. De acordo com o censo da educação superior, realizado em 2015, as mulheres representam 60\% das pessoas que concluíram cursos superiores no Brasil. Entretanto, levando-se em consideração apenas os cursos relacionados às ciências (engenharias, matemática, física, ciência da computação, entre outros), a participação feminina cai para 41\%, índice que não registra aumento desde 2000.

Além disso, um estudo similar conduzido por [Maia 2016], mas envolvendo somente cursos de computação, demonstrou que, no Brasil, apenas $17 \%$ dos concluintes são alunos do sexo feminino. Esse cenário de desproporcionalidade também pode ser observado no IFMG - campus Ouro Branco, onde apenas $22.7 \%$ do total de estudantes ativos 
no curso de sistemas de informação são mulheres e, ainda, a entrada delas nesse curso tem diminuído ao longo dos anos.

Nota-se, portanto, que existe uma grave defasagem da presença feminina nesses espaços, o que gera impactos negativos. Como afirma [Machado 2020], essa disparidade traz a ideia de que tecnologia é uma área exclusiva para público masculino. Consequentemente, tem-se um problema de insegurança feminina ao atuar nesse segmento. Primeiro porque as mulheres são minoria em salas de aula. Depois, ao ingressar no mercado de trabalho, por ser mulher e, obviamente, por fazer parte da minoria, a sua competência é colocada em questionamento a todo instante [Cardoso and Hanashiro 2018] e [Piantino 2016].

Assim sendo, para auxiliar as atuais estudantes do curso de Sistema de Informação do IFMG - campus Ouro Branco a enfrentarem os desafios da vida acadêmica e profissional, foi criado no ano de 2020 o projeto de ensino "Vai, Meninas!". Portanto, este trabalho apresenta as principais atividades realizadas pelo projeto e, também, a percepção qualitativa acerca delas.

\section{Pesquisa diagnóstica com as alunas antes da atuação do projeto}

Antes da realização das ações do projeto, foi aplicado um questionário ${ }^{1}$ on-line, a fim de averiguar quais são as motivações, percepções e perspectivas futuras que as alunas possuem sobre o curso e a área. Para tanto, foi feita a coleta do termo de consentimento livre e esclarecido (TCLE) dos participantes. As respostas apuradas serviram, então, para planejar as atividades a serem desenvolvidas pelo projeto.

Ademais, o questionário contém 24 perguntas. Foram recebidas 17 respostas, representando aproximadamente a impressão de $61 \%$ das alunas regularmente matriculadas no curso. Os gráficos que apresentam os resultados dessa pesquisa podem ser consultados na íntegra através desse $l i n k^{2}$.

Pode-se afirmar que as alunas estão motivadas a finalizar o curso, além de receberem apoio familiar para tal. Elas relataram, ainda, que o que mais as impulsionam a seguir carreira no âmbito de tecnologia é o sonho de ser uma profissional valorizada na empresa. Entretanto, quando questionadas a respeito de seu conhecimento prévio sobre a área, constata-se que mais da metade das alunas entrevistadas $(58,8 \%)$ não têm nenhum conhecimento prévio da área, enquanto que as demais têm pouca afinidade com assuntos relacionados à tecnologia. Isso é evidenciado nos gráficos (a) e (b) da Figura 1.

Somado a isso, as alunas também apresentaram as suas opiniões em relação a possibilidade de desistir do curso. A Figura 2, gráfico (a), mostra que $76.5 \%$ delas já pensaram em desistir do curso. Elas alegaram que os principais fatores para tal decisão seriam: i) dificuldades e reprovações nas disciplinas; ii) falta de oportunidade e pouca experiência prática e iii) cansaço por conta da carga horária ou necessidade de trabalhar e estudar (vide Figura 2, gráfico (b)).

De modo geral, pode-se concluir que as alunas pretendem finalizar seu curso, haja vista que enxergam na área de tecnologia boas perspectivas futuras de trabalho. Entretanto, essa perspectiva positiva pode ser afetada em virtude das dificuldades relatadas,

\footnotetext{
${ }^{1}$ As perguntas que compuseram o questionário aplicado pode ser visualizadas em: https://forms.gle/7DjWm4wELvEDY6JNA.

${ }^{2}$ https://bit.ly/2OY88Em .
} 


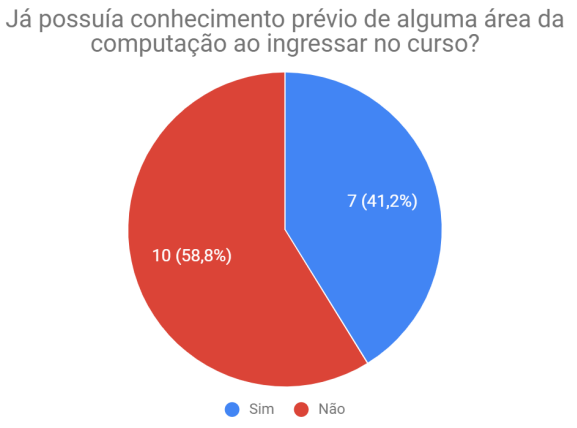

(a) Conhecimento prévio.

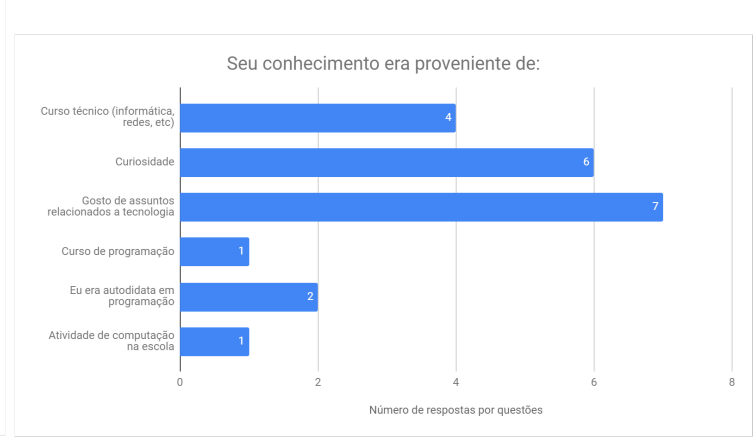

(b) Origem do conhecimento prévio.

Figura 1. Conhecimento prévio sobre a área de computação.

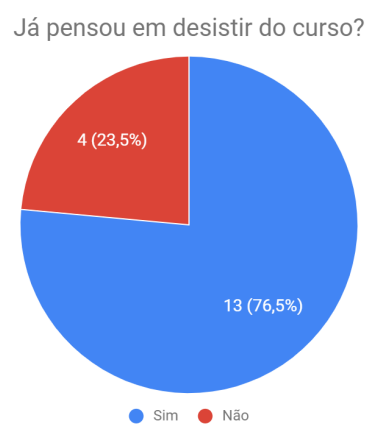

(a) Possibilidade de desistir do curso.

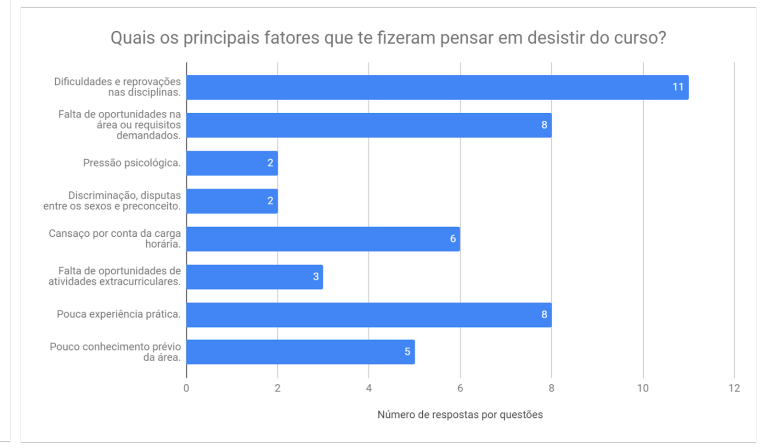

(b) Fatores que levaram as alunas a pensar em desistir do curso.

Figura 2. Possibilidade e Fatores de desistir do curso.

tais como o fato de não possuírem conhecimento prévio, pouca afinidade com a área e as reprovações nas disciplinas. Dessa maneira, entende-se que o projeto deve propor ações e atividades que possam ajudar as estudantes a superarem tais dificuldades e impulsioná-las na busca por seus ideais profissionais.

\section{Sobre o projeto: objetivos e motivação}

O projeto de ensino "Vai, Meninas!" foi proposto com o objetivo principal de criar um grupo de discussão de temas e de realização de atividades que visem ao encorajamento e ao fortalecimento das estudantes do curso de Sistema de Informação, para, assim, ajudálas a enfrentar os desafios da vida acadêmica e profissional.

\subsection{Metodologia}

O projeto foi executado por três professoras e duas estudantes bolsistas. Foram desenvolvidas no total 7 atividades no período entre setembro/2020 a março/2021, sendo que algumas delas se desdobraram em mais de um encontro.

Todas as atividades ocorreram de maneira virtual, via Google Meet, dado o cenário de isolamento social e ensino remoto emergencial imposto pela pandemia do novo coronavírus. Participaram dos encontros estudantes, professores e demais membros da comunidade interna do IFMG - campus Ouro Branco. 
O propósito de cada reunião foi desenvolver ações que fomentassem suas habilidades, divulgassem a área de tecnologia ou amparassem dificuldades técnicas ou pessoais. Assim, palestras, rodas de conversas com profissionais e ex-alunas, minicursos e ações voluntárias para o desenvolvimento de uma cultura de sororidade na comunidade fizeram parte das propostas de atividades do projeto. A Tabela, disponível neste link ${ }^{3}$, exibe maiores detalhes sobre os eventos promovidos.

Além da promoção de atividades virtuais, o projeto criou um canal de comunicação com as alunas via Instagram e Facebook. Ambos serviram como veículo para divulgação de conteúdos sobre a área de tecnologia, tais como quizzes sobre mulheres que fizeram história nas áreas de exatas; dicas de canais para aprendizado de programação e eventos externos, reportagens, artigos, oportunidades de estágio e de trabalho. O perfil do projeto conta atualmente com 200 seguidores e já promoveu mais de 50 publicações. Todo o conteúdo divulgado pode ser conferido na íntegra através deste link $k^{4}$. Vale ressaltar que um canal do youtube também foi criado para disponibilizar todo o conteúdo digital produzido.

\section{Percepções qualitativas acerca das atividades desenvolvidas pelo projeto}

Ao final de cada evento promovido pelo projeto, um questionário on-line foi elaborado e repassado às participantes a fim de entender suas opiniões a respeito das ações promovidas. A seguir será descrito as percepções qualitativas captadas em cada um desses eventos.

\subsection{Encontro com ex alunas das áreas de tecnologia e engenharia}

- As alunas entenderam que as colegas passaram pelas mesmas dificuldades que elas passam;

- Compartilharam conhecimento, dicas, incentivos e oportunidades;

- As alunas perceberam que profissionais com origens semelhantes a elas conseguiram dar saltos significativos em suas carreiras.

\subsection{Curso introdutório de Laravel}

- Para muitas alunas estudar um framework de desenvolvimento web sozinha pode ser uma tarefa um tanto quanto difícil. Porém, fazer isso em grupo tornou esse estudo mais simples e permitiu reforçar conhecimentos básicos de lógica e de linguagens para desenvolvimento web.

\subsection{Café com "Vai, Meninas!" e Treinamento de gravação de videoaula com as professoras de educação infantil e ensino fundamental}

- As alunas com mais dificuldades em disciplinas técnicas perceberam que o que já sabem pode ser muito útil para outras pessoas;

- Foi gratificante poder usar seus conhecimentos para mudar a realidade de outras mulheres que passam por desafios tecnológicos;

- As alunas entenderam o conceito de sororidade e o aplicaram na prática;

- Grupos de estudo foram estabelecidos entre as alunas.

\footnotetext{
${ }^{3}$ encurtador.com.br/dOUZ8

${ }^{4}$ http://bit.ly/3s3wrzf
} 


\subsection{Bate papo com psicólogos}

- As alunas nos relataram sentimentos de gratidão e felicidade, pois receberam orientações de como lidar com situações preconceituosas e/ou de assédios, seja no ambiente escolar ou em outras atividades profissionais e pessoais.

\subsection{Eventos de abertura e encerramento do projeto}

- As alunas viram, em mulheres com histórias de vida semelhantes às delas, o quão longe podem chegar com um trabalho sistemático, organizado e com dedicação contínua.

\section{Conclusão}

Neste trabalho foram apresentadas as principais atividades realizadas pelo projeto de ensino "Vai, Meninas!" e a percepção qualitativa colhida através de feedbacks com os participantes. Cada atividade desenvolvida teve o intuito de trabalhar cada uma das dificuldades elencadas a partir da pesquisa diagnóstica feita com as estudantes do Curso de Sistema de Informação.

A previsão original era que o projeto ocorresse presencialmente ao longo de 10 meses durante o ano de 2020. Em função da pandemia, o cronograma precisou passar por adequações, o que não impactou a qualidade das entregas e o atendimento dos seus objetivos. O engajamento das alunas (e de toda comunidade acadêmica) e feedbacks recebidos foram positivos. O projeto conseguiu aumentar a motivação das atuais alunas, através da disseminação da cultura de apoio mútuo, compartilhamento e geração de novos conhecimentos entre elas. Inclusive, entre as participantes, é unânime o desejo de que o projeto continue promovendo ações semelhantes àquelas que foram desenvolvidas para as atuais e futuras integrantes do curso.

Uma grande conquista deste projeto foi o reconhecimento que recebeu na Semana Nacional de Ciência e Tecnologia do IFMG. O projeto foi contemplado entre os 3 melhores projetos de ensino de 2020.

Como perspectivas futuras para o projeto se faz necessário pensar em outras ações para promover o fortalecimento acadêmico e profissional, bem como também a proposição de ações que possam impactar positivamente a comunidade externa e que sejam capazes de atrair mais mulheres para os cursos da área de tecnologia ofertados no Campus.

\section{Referências}

Cardoso, A. and Hanashiro, D. M. M. (2018). Percepção masculina sobre as barreiras das mulheres executivas. Revista Pretexto, 19(1):73-89.

Machado, G. M. (2020). A questão de gênero na área de tecnologia e inovação. Monografia (Tecnólogo em Gestão da Tecnologia da Informação), IFSC (Instituto Federal de Santa Catarina), Florianópolis, Brasil.

Maia, M. M. (2016). Limites de gênero e presença feminina nos cursos superiores brasileiros do campo da computação. cadernos pagu, (46):223-244.

Piantino, D. C. (2016). Impacto de estereótipo de baixa performance de mulheres em ciências exatas na tomada de decisão. 